\title{
Angka Indeks Tertimbang dan Tidak Tertimbang
}

Disusun Oleh :

-Agus Bahri Rahman (17190369) Semester 3

-Rehan Hardiansyah (17190551) Semester 3

-Bryan Eric Kurniawan (17190777) Semester 3 


\section{Angka Indeks}

Angka indeks adalah peralatan statistik yang sangat popular guna mengukur perubahan atau melakukan perbandingan antara variabel ekonomi dan social. Perubahan atau perbandingan antara variabel dari waktu ke waktu dan dinyatakan dengan angka-angka indeks umumnya lebih mudah dimengerti.

Dalam pembuatan angka indeks diperlukan 2 macam periode, yaitu : -Periode waktu dasar (Base period)

-Periode waktu yang sedang berjalan (Current Period) 


\section{Periode Waktu Dasar (Base Period)}

Waktu di mana suatu kegiatan (kejadian) dipergunakan untuk dasar perbandingan. Periode dasar biasanya dinyatakan dalam angka indeks sebesar 100 .

\section{Periode Waktu Yang Sedang Berjalan (Current Period)}

Waktu di mana suatu kegiatan akan diperbandingkan terhadap kegiatan pada waktu dasar. Periode berjalan disebut juga sebagai periode bersangkutan. 


\section{Pemilihan Tahun Dasar.}

Beberapa syarat yang perlu diperhatikan dalam menentukan atau memilih waktu dasar adalah

1. Waktu sebaiknya menunjukkan keadaan perekonomian yang stabil, di mana harga tidak berubah dengan cepat sekali.

2. Waktu sebaiknya usahakan paling lama 10 tahun atau lebih baik kurang dari 5 tahun.

3. Waktu di mana terjadi peristiwa penting.

4. Waktu di mana tersedia data untuk keperluan pertimbangan, hal ini tergantung pada tersedianya biaya untuk penelitian (pengumpulan data). 


\section{Sistematika Angka Indeks}

\section{Angka Indeks}

Angka Indeks Sederhana

$>$ Bentuk Relatif

$>$ Bentuk Agretatif

$>$ Angka Indeks Harga

$>$ Angka Indeks Kuantitas

$>$ Angka Indeks Nilai
Angka Indeks Tertimbang

$>$ Bentuk Relatif

$>$ Bentuk Agretatif

$>$ Angka Indeks Harga

$>$ Angka Indeks Kuantitas

$>$ Angka Indeks Nilai 


\section{Indeks Tertimbang}

Macam - macam metode perhitungan tertimbang, yaitu:

$\diamond$ Indeks harga agretatif tertimbang.

$\diamond$ Indeks produksi agretatif tertimbang.

$\diamond$ Variasi dari indeks harga tertimbang.

$\diamond$ Variasi dari indeks produksi tertimbang. 


\section{Keterangan Rumus}

$\diamond \mathrm{It}, 0=$ Angka indeks tahun ke-t dibandingkan dengan tahun dasar

$\diamond \mathrm{P}_{\mathrm{t}}=$ Harga masing-masing produk pada tahun ke- $\mathrm{t}$

$\diamond \mathrm{P}_{0}=$ Harga masing-masing produk pada tahun dasar

$\diamond \mathrm{Q}_{\mathrm{t}}=$ Kuantitas masing-masing produk pada tahun ke- $\mathrm{t}$

$\diamond Q_{0}=$ Kuantitas masing-masing produk pada tahun dasar

$\diamond \mathrm{n}=$ Banyaknya produk yang diobservasi 


\section{Indeks Harga Agretatif Tertimbang}

$\diamond$ Ada 2 metode yang digunakan dalam perhitungan ini, yaitu:

Indeks Laspeyres

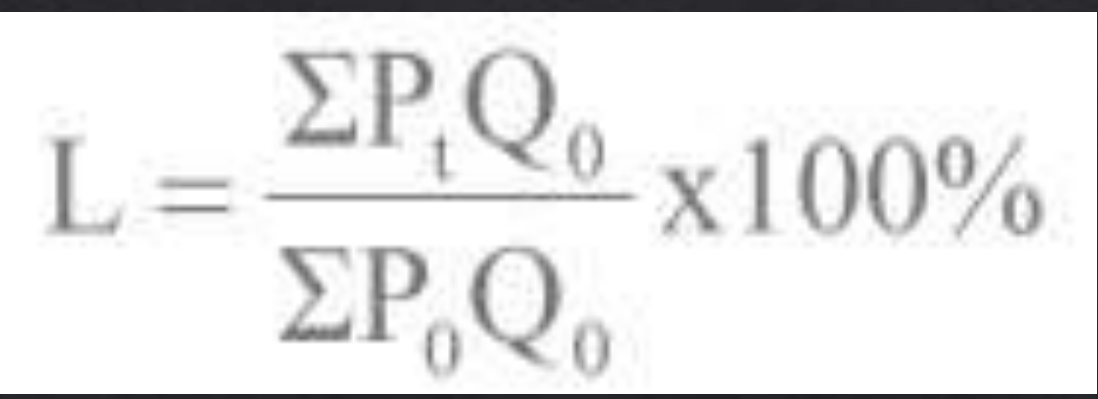

Metode Laspeyres menerapkan jumlah barang pada tahun dasar menjadi timbangan terhadap suatu harga. Anggapan yang mendasari metode ini ialah kuantitas (jumlah) barang tidak berubah dari tahun ke tahun sejak tahun dasar. dan

Indeks Paasche

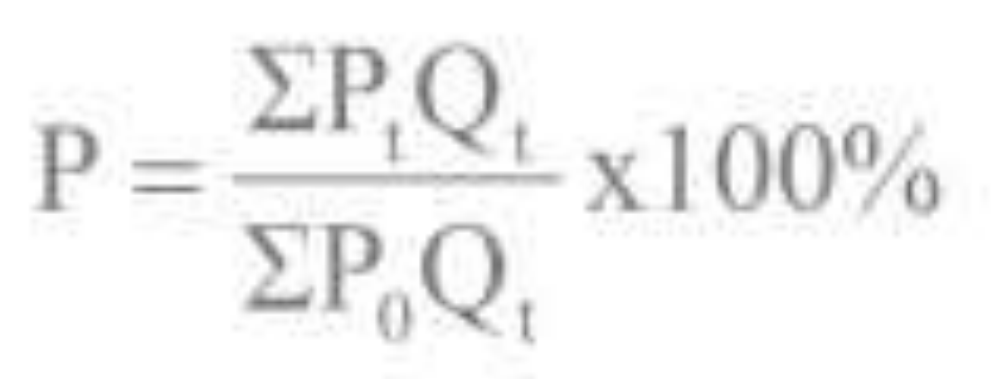

Metode Paasche memakai kuantitas (jumlah) barang pada tahun yang berjalan atau tahun yang dipakai sebagai timbangan terhadap harga. Dalam metode Paasche ini mengasumsikan bahwa jumlah barang itu bisa mengalami perubahan dari tahun ke tahun. 


\section{Indeks Produksi Agretatif Tertimbang}

$\diamond$ Ada 2 metode yang digunakan dalam perhitungan ini, yaitu:

Indeks Laspeyres

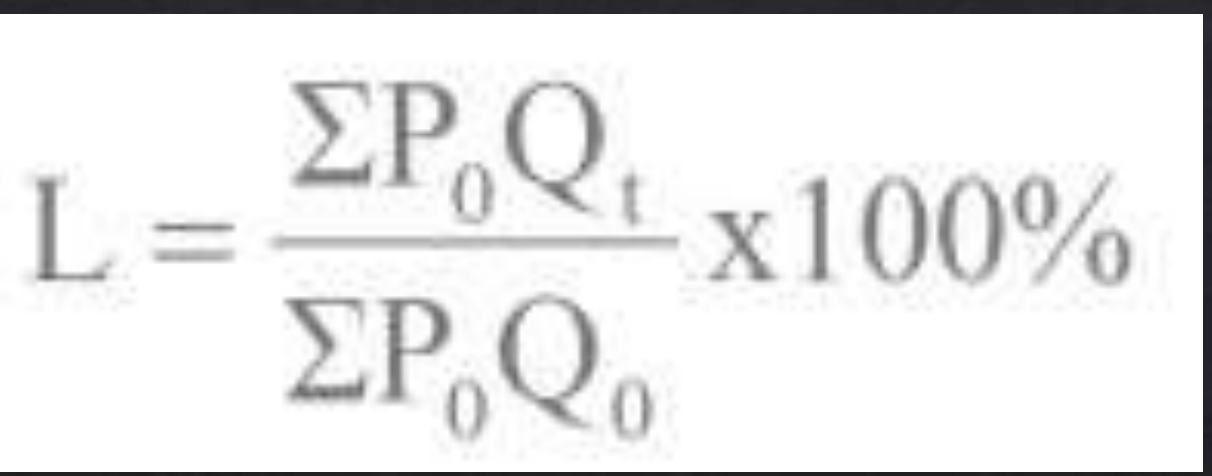

dan

Indeks Paasche

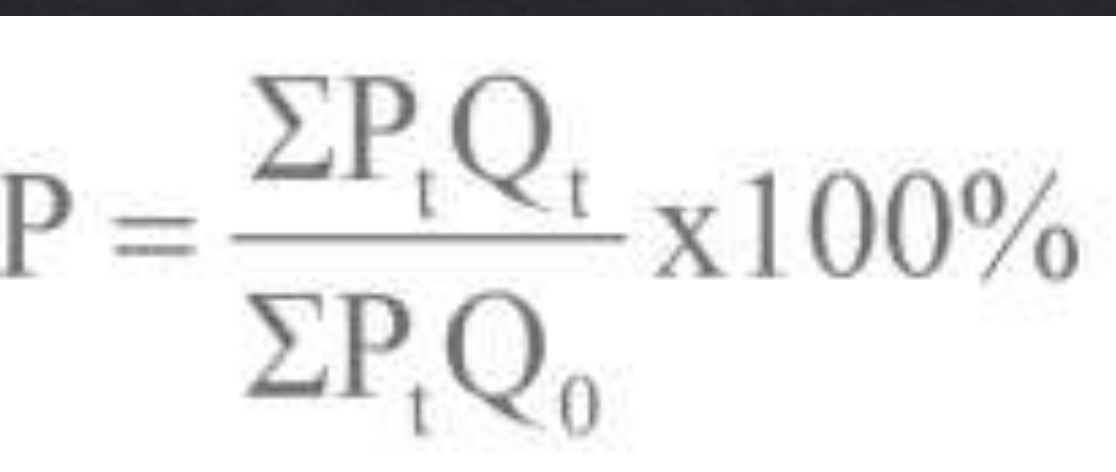


Variasi dari Indeks Harga Tertimbang

Indeks Fischer

$\mathbf{I}=\sqrt{\mathbf{L}_{\text {Haryin }} \mathbf{x} \mathbf{P}_{\text {thatge }}}$ dan

Indeks Drobisch

Variasi dari Indeks Produksi Tertimbang

Indeks Fischer

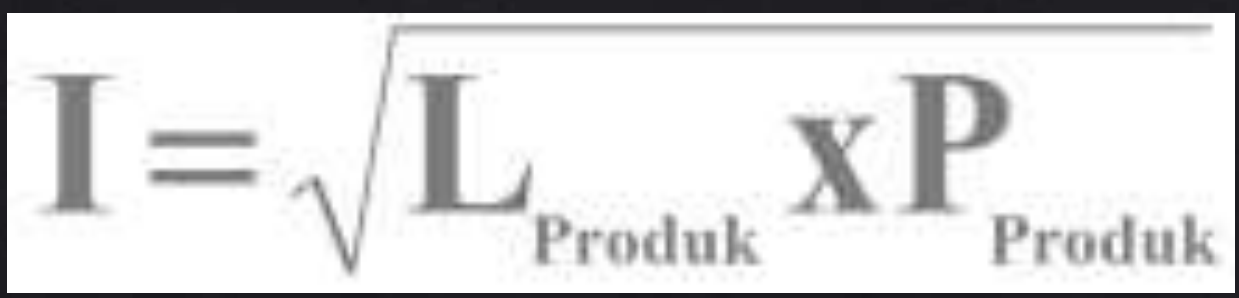

dan

Indeks Drobisch 


\section{Indeks Tidak Tertimbang}

$\diamond$ Indeks harga relatif sederhana adalah indeks yang terdiri dari satu macam barang saja baik untuk indeks produksi maupun indeks harga misalnya indeks produksi ikan, indeks harga beras dll.

$\diamond$ Indeks Agregatif adalah indeks yang terdiri dari beberapa barang (kelompok barang) misalnya indeks harga 9 bahan pokok. 
Macam-macam metode perhitungan tak tertimbang, yaitu:

* Angka Indeks Sederhana Relatif Harga.

* Angka Indeks Sederhana Relatif Kuantitas.

* Angka Indeks Sederhana Harga Agregatif.

* Angka Indeks Sederhana Kuantitas Agretatif.

* Angka Indeks Sederhana Harga Rata-rata Relatif.

* Angka Indeks Sederhana Kuantitas Rata-rata Relatif. 


\section{$\underline{\text { RUMUS }}$}

$\diamond$ Angka Indeks Sederhana Relatif Harga

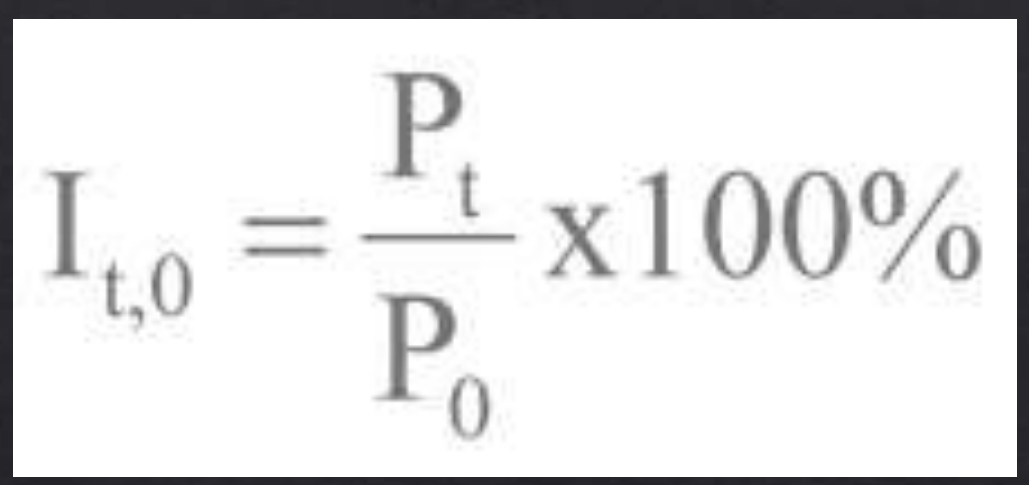

$\diamond$ Angka Indeks Sederhana Relatif Kuantitas

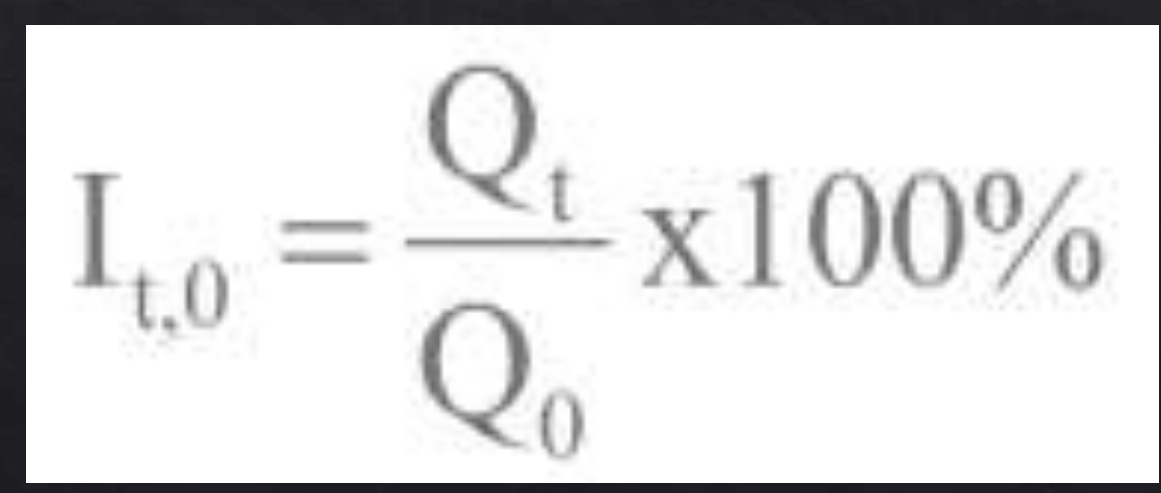




\section{$\underline{\text { RUMUS }}$}

$\diamond$ Angka Indeks Sederhana Harga Agretatif

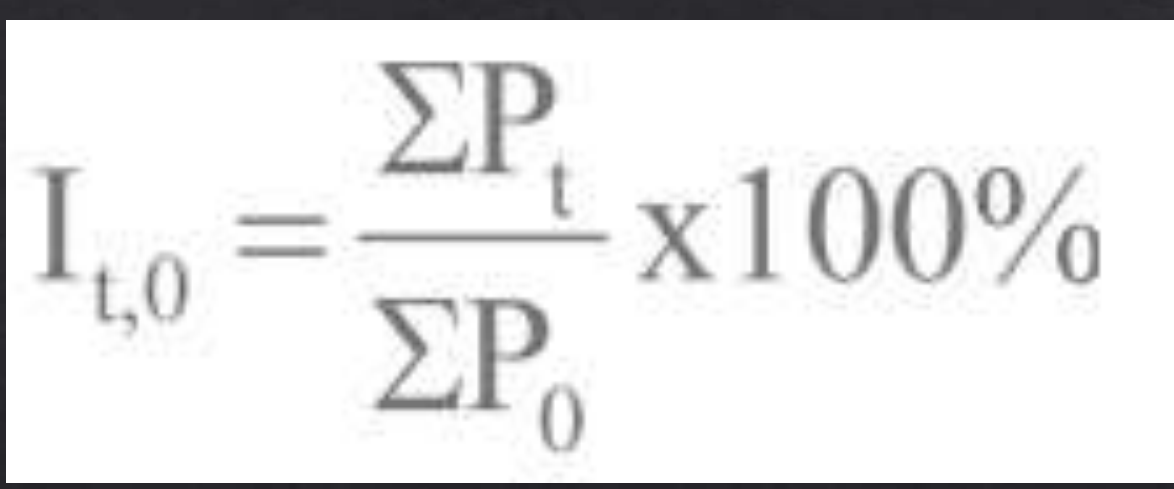

$\diamond$ Angka Indeks Sederhana Kuantitas Agretatif

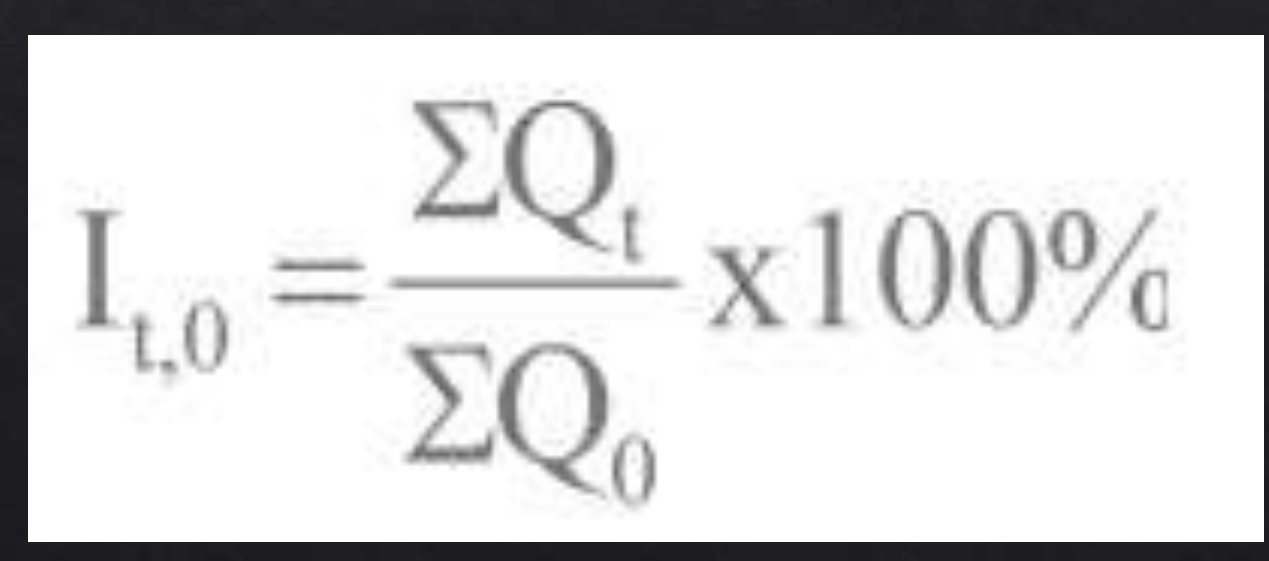




\section{$\underline{\text { RUMUS }}$}

$\diamond$ Angka Indeks Sederhana Harga Rata-rata Relatif

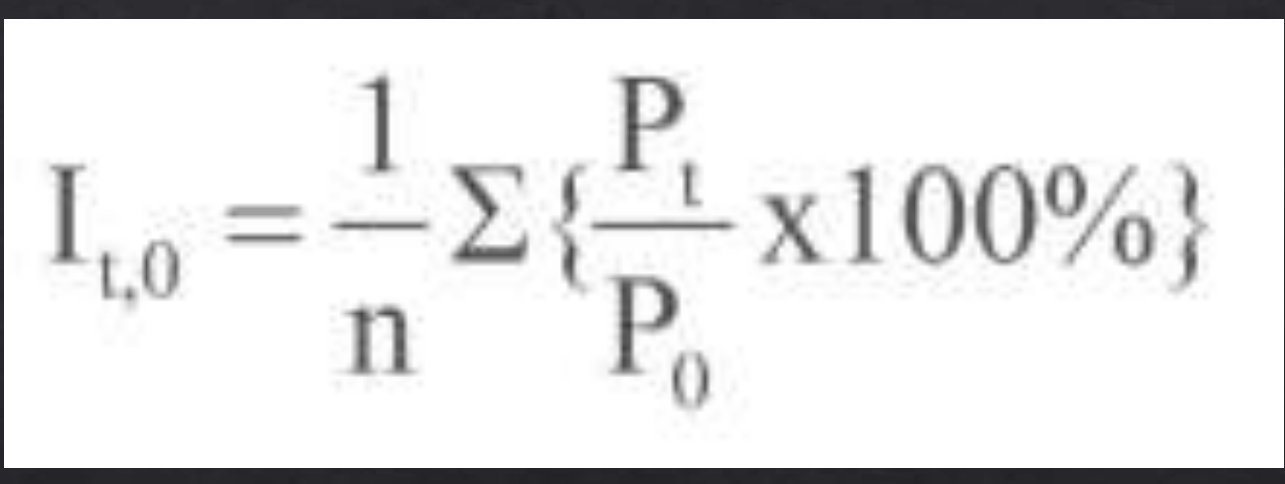

$\diamond$ Angka Indeks Sederhana Kuantitas Rata-rata Relatif

$$
\mathrm{I}_{\mathrm{t}, 0}=\frac{1}{\mathrm{n}} \Sigma\left\{\frac{\mathrm{Q}_{\mathrm{t}}}{\mathrm{Q}_{0}} \times 100 \%\right\}
$$




\section{Hasil Studi Kasus}

Mengenai Perubahan Harga Pangan Per Tahun

$\diamond$ Indeks Tertimbang

Perubahan Harga Pangan Per Tahun

\begin{tabular}{|c|c|c|c|c|c|}
\hline \multirow{2}{*}{ NO } & \multirow{2}{*}{ Macam Barang } & \multicolumn{2}{|c|}{ Harga } & \multicolumn{2}{|c|}{ Kuantitas } \\
\hline & & $2018(\mathrm{Po})$ & $2020(\mathrm{Pn})$ & $2018(\mathrm{Qo})$ & $2020(\mathrm{Qn})$ \\
\hline 1 & Beras Premium & 12.500 & 12.000 & 17 & 22 \\
\hline 2 & Jagung $P_{\text {ipih }}$ & 3.600 & 8.000 & 30 & 25 \\
\hline 3 & Bawang Merah & 12.000 & 50.000 & 15 & 30 \\
\hline 4 & Gula Pasir & 11.500 & 16.000 & 5 & 15 \\
\hline 5 & Daging Ayam & 28.000 & 30.000 & 14 & 20 \\
\hline 6 & Daging Sapi & 80.000 & 120.000 & 30 & 25 \\
\hline 7 & Telux Ayam & 23.000 & 23.000 & 25 & 30 \\
\hline 8 & Cabe Rawit & 25.000 & 40.000 & 35 & 40 \\
\hline
\end{tabular}




\section{Hitung Indeks Harga Agretatif Tertimbang}

$\diamond$ Menggunakan Metode Paasche

\begin{tabular}{|r|r|}
\hline \multicolumn{2}{|c|}{ Metode Paasche } \\
\hline Pn $x$ Qn & \multicolumn{1}{|c|}{ Pox Qn } \\
\hline 264000 & 275000 \\
\hline 200000 & 90000 \\
\hline 1500000 & 360000 \\
\hline 240000 & 172500 \\
\hline 600000 & 560000 \\
\hline 3000000 & 2000000 \\
\hline 690000 & 690000 \\
\hline 1600000 & 1000000 \\
\hline 8094000 & 5147500 \\
\hline
\end{tabular}

Masukan Rumus Indeks Paasche :

$$
\begin{aligned}
& \mathrm{P}=\frac{(\mathrm{Pn} \times \mathrm{Qn})}{(\mathrm{Po} \times \mathrm{Qn})} \times 100 \% \\
& \mathrm{P}=\frac{8094000}{5147500} \times 100 \%=157,2413793
\end{aligned}
$$




\section{Hitung Indeks Harga Agretatif Tertimbang}

$\diamond$ Menggunakan Metode Laspeyres

\section{Metode Laspeyres}

\begin{tabular}{|r|r|}
\hline \multicolumn{1}{|c|}{ Pn $\mathbf{x}$ Qo } & \multicolumn{1}{c|}{ Pox $\mathrm{Qo}$} \\
\hline 204000 & 212500 \\
\hline 240000 & 108000 \\
\hline 750000 & 180000 \\
\hline 80000 & 57500 \\
\hline 420000 & 392000 \\
\hline 3600000 & 2400000 \\
\hline 575000 & 575000 \\
\hline 1400000 & 875000 \\
\hline 7269000 & 4800000 \\
\hline
\end{tabular}

Masukan Rumus Indeks Laspeyres

$$
\begin{aligned}
L & =\frac{(\text { Pn } \times \text { Qo })}{(\text { Po } \times \text { Qo })} \times 100 \% \\
L & =\frac{7269000}{4800000} \times 100 \%=151,4375
\end{aligned}
$$




\section{Hitung Variasi dari Indeks Harga Tertimbang}

$\diamond$ Menggunakan Metode Fischer

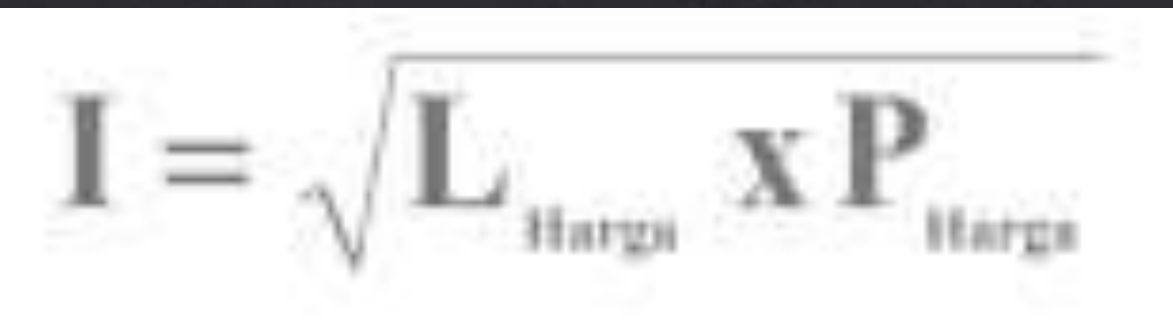

$$
\begin{aligned}
& I=\sqrt{ }(151,4375 \times 157,2413793) \\
& I=154,3394397
\end{aligned}
$$

$\diamond$ Menggunakan Metode Drobisch

$$
I=1 / 2\left(L_{\text {Harga }}+P_{\text {Harga }}\right)
$$

$1=1 / 2(151,4375+157,2413793)$

$1=154,33943965$ 
$\diamond$ Indeks Tak Tertimbang

\section{Perubahan Harga Pangan Per Tahun}

\begin{tabular}{|c|c|c|c|}
\hline $\mathrm{NO}$ & Jenis Barang & $\begin{array}{c}\text { Harga } \\
2012(\mathrm{Po})\end{array}$ & $\begin{array}{l}\text { Harga } 2014 \\
(\mathrm{Pn})\end{array}$ \\
\hline 1 & Bawang Putih & 400 & 450 \\
\hline 2 & Jagung & 300 & 200 \\
\hline 3 & Beras Merah & 200 & 550 \\
\hline 4 & Daging Sapi & 100 & 450 \\
\hline 5 & Bawang Merah & 500 & 100 \\
\hline & Jumlah & 1500 & 1750 \\
\hline
\end{tabular}




\section{Hitung Angka Indeks Sederhana Harga Agretatif}

$\diamond$ Masukan Rumusnya

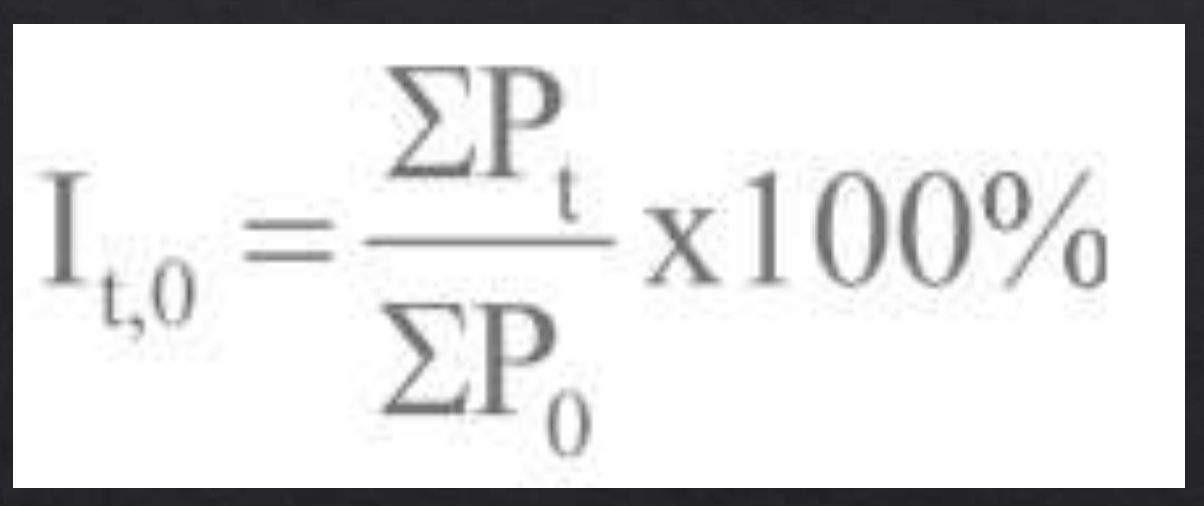

$=\frac{1750}{1500} \times 100 \%=116,6667$ 
Hitung Angka Indeks Sederhana Harga Rata-rata Relatif

$\diamond$ Masukan Rumusnya

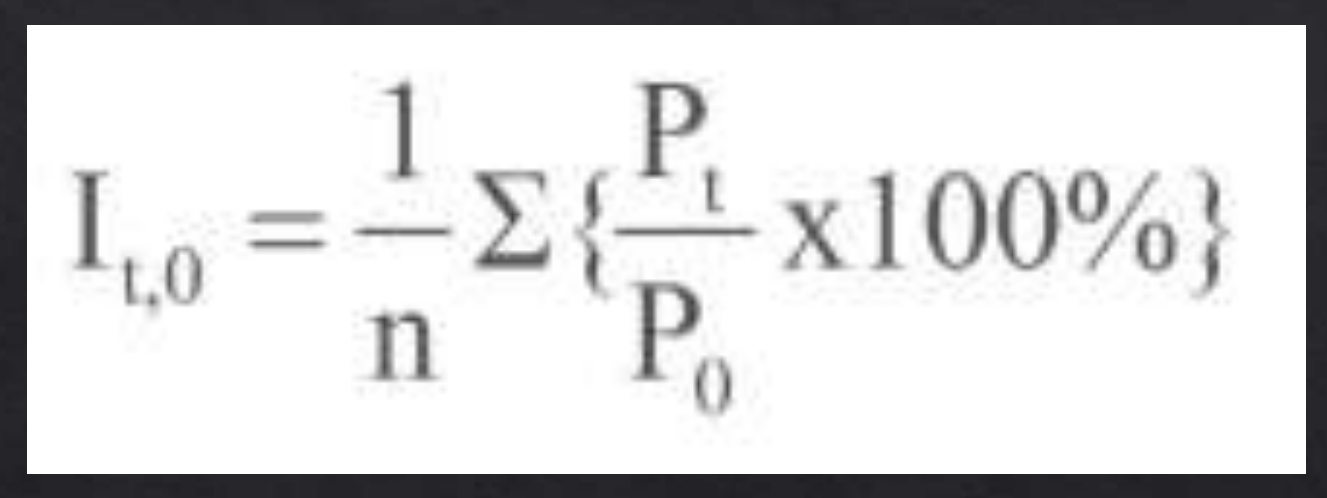

$$
=\frac{1}{5} \times \frac{1750}{1500} \times 100 \%=23,33333
$$

